Anna Babicka-Wirkus

Akademia Pomorska w Słupsku

anna.babicka-wirkus@apsl.edu.pl

ORCID: 0000-0002-1292-7351 kukasz Wirkus

Uniwersytet Gdański

lukasz.wirkus@ug.edu.pl

ORCID: 0000-0003-2281-0939

\title{
Nowe wyzwania Kuratorskiej Służby Sądowej. Przygotowanie kulturowe kuratorów sądowych do pracy z obcokrajowcami
}

\section{Wprowadzenie}

Wśród instytucji zajmujących się specyficznymi problemami cudzoziemców w Polsce znajduje się Kuratorska Służba Sądowa. Rolę kuratorów sądowych określono w ustawie o kuratorach sądowych'1, która jest podstawowym aktem prawnym regulującym działalność Kuratorskiej Służby Sądowej (KSS). Kuratorzy sądowi wykonują wiele istotnych zadań w obszarze wymiaru sprawiedliwości, które są zróżnicowane ze względu na specjalizację karną i rodzinną². Kuratorzy sądowi dzielą się na kuratorów zawodowych i społecznych (wolontariuszy), którzy wykonują orzeczenia w sprawach karnych (kuratorzy dla dorosłych) lub w sprawach rodzinnych i wobec nieletnich (kuratorzy rodzinni) ${ }^{3}$. Na koniec 2019 r. KSS obejmowała 5.113,5 etatów kuratorów zawodowych. Kuratorzy wykonują swoje zadania w 559 zespołach kuratorskiej służby sądowej. Kuratorzy zawodowi współpracują z grupą 18.413 kuratorów społecznych i prowadzili w 2019 r. łącznie 398.923 spraw4. Wśród wielu zadań realizowanych na co dzień przez KSS pojawia się kwestia regularnych kontaktów z cudzoziemcami, których sprawy trafiają do kuratorów sądowych w związku z wyrokami karnymi lub postępowaniami prowadzonymi przez sądy rodzinne. Praca z cudzoziemcami i przygotowanie kulturowe kuratorów sądowych do jej wykonywania, stały się współcześnie wyzwaniem dla tej grupy zawodowej ${ }^{5}$.

1 Ustawa z dnia 27 lipca 2001 r. o kuratorach sądowych (Dz. U. Nr 98, poz. 1071 ze zm.; dalej: u.k.s.).

2 Zadania kuratorów dla dorosłych i zadania kuratorów rodzinnych szczegółowo opisali: T. Jedynak i K. Stasiak, Zadania kuratorów sqdowych [w:] Zarys metodyki pracy kuratora sq̨dowego, red. K. Stasiak, Warszawa 2018.

3 Art. 1-3 u.k.s.

4 J. Wacławiak, Tendencje zmian w zakresie spraw rejestrowanych w MS-S40. Analiza porównawcza danych z 31.12.2019 do danych z 31.12.2018 roku (na podstawie MS-S40), Warszawa 2020.

5 Ł. Wirkus, Czynności służbowe kuratora rodzinnego z udziałem cudzoziemców - studium przypadku, „Lubelski Rocznik Pedagogiczny" 2019, z. 2, s. 169-189 
Celem artykułu jest zwrócenie uwagi na palący problem przygotowania kulturowego kuratorów sądowych do pracy z podopiecznymi, którzy są cudzoziemcami oraz stworzenie katalogu rekomendacji usprawnienia praktyki postępowania wykonawczego. Kwestia przygotowania kulturowego kuratorów sądowych staje się w ostatnich latach coraz bardziej istotna w związku ze zwiększającą się liczbą obcokrajowców przybywających do Polski na pobyt czasowy lub stały ${ }^{6}$. Stawiamy tezę, że przygotowanie kuratorów sądowych, ale też wymiaru sprawiedliwości, pod względem pracy z osobą pochodzącą z innej kultury, posługującą się językiem obcym, jest niewystarczające i wymaga gruntownych badań oraz usprawnienia. Problem ten pogłębia się wraz z brakiem przepisów prawa, które systemowo regulowałoby różnego rodzaju kwestie organizacyjne w prowadzonych przez kuratorów postępowaniach wykonawczych w związku z obcokrajowcami.

\section{Cudzoziemcy w Polsce}

Urząd do Spraw Cudzoziemców podaje, że na początku 2020 r. prawie 423 tys. cudzoziemców miało ważne zezwolenia na pobyt w Polsce. Wśród nich największe grupy stanowili obywatele Ukrainy - 214,7 tys. osób, Białorusi - 25,6 tys. osób, Niemiec - 21,3 tys. osób, oraz Rosji - 12,5 tys. i Wietnamu - 12,1 tys. W dalszej kolejności są obywatele Indii - 9,9 tys., Włoch - 8,5 tys. osób, Chin - 8,5 tys. osób, oraz Wielkiej Brytanii - 6,3 tys., i Hiszpanii - 5,9 tys. osób7. Ponad połowa cudzoziemców (57\%) to osoby w przedziale wiekowym 20-39 lat, prawie 26\% w przedziale 40-59 lat, a 12\% stanowią osoby poniżej 20. roku życia ${ }^{8}$. Prognozy Ośrodka Badań nad Migracjami Uniwersytetu Warszawskiego wskazują, że do 2050 r. Polskę zamieszkiwać będzie nawet ponad 3,5 mln cudzoziemców ${ }^{9}$. Część z nich już podjęła decyzję o ściągnięciu do Polski swoich bliskich i tutaj znajduje się centrum życiowe ich rodzin, a wielu rozważa taki pomysł. Konsekwencją tej sytuacji jest zmieniająca się struktura społeczeństwa, która staje się coraz bardziej multikulturowa. Skutkami tego procesu może być występowanie różnego rodzaju zjawisk społecznych, m.in.: zjawisko przestępczości z udziałem

\footnotetext{
6 Main direction of emigration and immigration in the years 1966-2018 (migration for permanent residence), https://stat.gov.pl/en/topics/population/internationa-migration/main-directions-of-emigration-and-immigration-in-the-years-1966-2018-migration-for-permanent-residence,2,2.html [dostęp: 3.04.2020].

7 Urząd do Spraw Cudzoziemców, Zezwolenia na pobyt po I kwartale 2020 r., https://udsc.gov.pl/zezwolenia-na-pobyt-po-i-kwartale-2020-r/ [dostęp: 15.04.2020].

8 K. Sobczak, Więcej cudzoziemców przebywa legalnie w Polsce, https://www.prawo.pl/prawo/ cudzoziemcy-w-polsce-na-poczatku-2020-r-423-tys-osob-przebywalo,497222.html [dostęp: 23.03.2020].

9 https://motivated-workers.eu/imigranci-w-polsce-statystyki [dostęp: 28.03.2020].
} 
obcokrajowców ${ }^{10}$, występowanie przemocy ${ }^{11}$, dyskryminacja i nierówne traktowanie ${ }^{12}$, zaniedbania opiekuńczo-wychowawcze ${ }^{13}$ czy zjawisko niedostosowania społecznego dzieci i młodzieży ${ }^{14}$.

\section{Problem przestępczości obcokrajowców w Polsce}

Ostatnie ogólnodostępne dane dotyczące przestępczości cudzoziemców w Polsce pochodzą z 2012 r. i są dostępne na stronie internetowej Komendy Głównej Policji oraz analizowane w publikacji Przestępczość cudzoziemców. Aspekty prawne, kryminologiczne i praktyczne $e^{15}$ z 2017 r. Na nowsze dane powołuje się dziennik "Rzeczpospolita", który podaje, że w latach 2016-2017 liczba przestępstw popełnianych przez obcokrajowców w naszym kraju wzrosła o 80\% ${ }^{16}$. W 2017 r. cudzoziemcy popełnili w Polsce 6264 przestępstw, z czego połowa miała charakter kryminalny. Najczęściej w 2017 r. przestępstwa popełniały osoby narodowości ukraińskiej i białoruskiej. $Z$ danych pochodzących z lat 2004-2012 wynika, że prawo polskie łamali głównie Ukraińcy i Niemcy ${ }^{17}$.

Ministerstwo Sprawiedliwości podaje, że dane statystyczne dotyczące liczby prawomocnie skazanych osób dorosłych cudzoziemców według rodzajów przestępstw, płci i wymiaru kary gromadzone są na podstawie bazy danych statystycznych Krajowego Rejestru Karnego w cyklach rocznych. W tabeli nr 1 zaprezentowaliśmy wyłącznie dane statystyczne dotyczące liczby prawomocnie skazanych osób dorosłych cudzoziemców według płci i rodzaju kary w okresie 2016-2018, które udostępniło ministerstwo.

10 I. Rzeplińska, K. Buczkowski, B. Czarnecka-Dzialuk et al., Społeczno-polityczne konteksty współczesnej przestępczości w Polsce, Warszawa 2013.

11 W. Klaus, Przemoc wobec migrantek przymusowych w Polsce - charakterystyka zjawiska [w:] Bezpieczny dom? Przemoc fizyczna i symboliczna wobec uchodźczyń i uchodźców, red. idem, Warszawa 2014.

12 W. Klaus, A. Winiarska, Dyskryminacja i nierówne traktowanie jako zjawisko społeczno-kulturowe, "Studia Biura Analiz Sejmowych" 2011, nr 2, s. 9-39.

13 I. Malorny, Zaniedbanie dziecka w rodzinie migracyjnej - aspekty społeczno-prawne, „Resocjalizacja Polska" 2015, nr 10, s.125-136.

14 I.M. Montgomery, Multicultural awareness: Developing cultural understanding in the juvenile justice system, ,Juvenile Probation Tricks of the Trade" 1992, vol. 1, no. 1; I. Rzeplińska, K. Buczkowski, B. Czarnecka-Dzialuk et al., Społeczno-polityczne konteksty...; Ł. Wirkus, The role of the family court in Poland in preventing manifestations of demoralization and juvenile delinquency on the example of preventive and re-socialization activities of probation officers, "The Polish Journal of Criminology" 2018, vol. 1, s. 70-89. 15 Przestępczość cudzoziemców. Aspekty prawne, kryminologiczne i praktyczne, red. W. Klaus, K. Laskowska, I. Rzeplińska, Warszawa 2017.

16 G. Zawadka, Cudzoziemcy popełniaja coraz więcej przestępstw w Polsce, "Rzeczpospolita” z dnia 22 marca 2018 r., https://www.rp.pl/Przestepczosc/303219904-Cudzoziemcy-popelniaja-corazwiecej-przestepstw-w-Polsce.html [dostęp: 2.04.2020].

17 I. Rzeplińska, J. Włodarczyk-Madejska, Przestępczość cudzoziemców w Polsce - na podstawie policyjnych statystyk przestępczości [w:] Przestępczość cudzoziemców. Aspekty prawne..., Warszawa 2017. 
Tabela nr 1. Prawomocnie skazani cudzoziemcy według płci i rodzaju kary w latach 2016-2018

\begin{tabular}{|c|c|c|c|c|c|c|c|c|c|c|c|c|}
\hline \multirow[t]{4}{*}{ Rok } & \multirow{3}{*}{\multicolumn{2}{|c|}{ Kara grzywny }} & \multirow{3}{*}{\multicolumn{2}{|c|}{$\begin{array}{c}\text { Kara ogra- } \\
\text { niczenia } \\
\text { wolności }\end{array}$}} & \multicolumn{6}{|c|}{ Kara pozbawienia wolności } & \multirow{3}{*}{\multicolumn{2}{|c|}{$\begin{array}{c}\text { Grzyw- } \\
\text { na obok } \\
\text { pozbawienia } \\
\text { wolności }\end{array}$}} \\
\hline & & & & & \multirow{2}{*}{\multicolumn{2}{|c|}{$\begin{array}{c}\text { bez } \\
\text { zawieszenia }\end{array}$}} & \multicolumn{4}{|c|}{ z zawieszeniem } & & \\
\hline & & & & & & & \multicolumn{2}{|c|}{ z dozorem } & \multicolumn{2}{|c|}{ bez dozoru } & & \\
\hline & M & K & M & K & M & K & M & K & M & K & $M$ & K \\
\hline 2016 & 4768 & 957 & 245 & 36 & 296 & 20 & 148 & 29 & 2329 & 493 & 794 & 93 \\
\hline 2017 & 4452 & 790 & 300 & 56 & 314 & 26 & 163 & 24 & 1877 & 350 & 623 & 76 \\
\hline 2018 & 5910 & 758 & 471 & 57 & 491 & 34 & 189 & 23 & 2140 & 265 & 740 & 67 \\
\hline
\end{tabular}

Źródło: opracowanie własne na podstawie informacji statystycznej z Wydziału Statystycznej Informacji Zarządczej, Departament Strategii i Funduszy Europejskich Ministerstwa Sprawiedliwości.

Na podstawie uzyskanych danych trudno określić dynamikę zjawiska przestępczości poza wyraźną tendencją wzrostową pomiędzy 2016 r. (osoby skazane łącznie 9337, w tym 7802 mężczyzn i 1535 kobiet) a 2018 r. (osoby skazane łącznie 10.368, w tym 9228 mężczyzn i 1140 kobiet). W 2017 r. prawomocnie skazano na różnego rodzaju kary 8379 cudzoziemców (w tym 7133 mężczyzn i 1246 kobiet). Zauważalna jest progresja zjawiska przestępczości wśród mężczyzn. Cudzoziemcy najczęściej popełniali przestępstwa sklasyfikowane w kodeksie karnym jako przestępstwa przeciwko: bezpieczeństwu w komunikacji, obrotowi gospodarczemu, wiarygodności dokumentów, mieniu, porządkowi publicznemu, a także przestępstwa sklasyfikowane w kodeksie karnym skarbowym, ustawie o przeciwdziałaniu narkomanii, prawie własności przemysłowej i innych ważnych aktach prawnych ${ }^{18}$. Dane statystyczne wskazują, że ze znaczą grupą skazanych cudzoziemców mają do czynienia kuratorzy sądowi w zakresie wykonywania przez te osoby kary ograniczenia wolności (prawie dwukrotny wzrost prawomocnych orzeczeń pomiędzy 2016-2018 r.), prowadzenia dozoru (wyraźna tendencja wzrostowa), czynności związanych z kontrolą okresu próby czy wykonania przez skazanych innych dolegliwości orzeczonych przez sąd, np. finansowych.

\section{Znaczenie przygotowania kulturowego w pracy kuratora sądowego}

Problematyka przygotowania kulturowego kuratorów sądowych wpisuje się także w obszary zainteresowania naukowego kryminologii kulturowej, poprzez przeplatanie

\footnotetext{
18 Wydział Statystycznej Informacji Zarządczej, Departament Strategii i Funduszy Europejskich Ministerstwa Sprawiedliwości, Dane statyczne dotyczące liczby prawomocnie skazanych osób dorosłych cudzoziemców według rodzajów przestępstw, płci i wymiaru kary w latach 2016-2018.
} 
się mechanizmów kulturowych życia codziennego z praktykami przestępczymi, praktykami kontroli społecznej i różnych kontekstów codzienności ${ }^{19}$. Natomiast szereg zagadnień związanych nie tylko ze sposobem życia cudzoziemców w Polsce i ich kontaktów z wymiarem sprawiedliwości, ale także ze stosunkiem obywateli i systemu do mniejszości etnicznych, religijnych, itp. pozostaje w relacji z koncepcją sprawiedliwości naprawczej. Wojciech Zalewski podkreśla istotę tego modelu, który "(...) wyraża głębokie zainteresowanie nie tylko naprawą szkody wyrządzonej w przeszłości, ale również stworzeniem lepszej przyszłości. Przyszłości, w której ludzie żyją w poprawnych materialnych, socjalnych i duchowych relacjach ze sobą. Ta przyszłość wymaga głębokiego wglądu w czynniki przyczyniające się do przestępstwa, tworzące konflikt i niesprawiedliwość, wymaga działania, które je złagodzi lub wyeliminuje"20. W tym kontekście szczególnego znaczenia nabierają kompetencje kulturowe. National Association of Social Workers promuje realizację tych kompetencji na trzech poziomach: indywidualnym, instytucjonalnym i społecznym. Kompetencje kulturowe wymagają zbadania przez funkcjonariuszy służb społecznych ich własnego pochodzenia kulturowego i tożsamości. Samoświadomość kulturowa jest istotna w procesie zdobywania niezbędnej wiedzy i umiejętności z zakresu relacji wielokulturowych, które mogą poprawić jakość usług dla osób reprezentujących mniejszości kulturowe, w aspekcie rasy, pochodzenia etnicznego, płci, pochodzenia społecznego, orientacji seksualnej, religii, wieku lub niepełnosprawności. Bycie kulturowo kompetentnym w obszarze międzykulturowego funkcjonowania oznacza uczenie się nowych wzorców zachowań i stosowanie ich w odpowiednich sytuacjach ${ }^{21}$. Zdolność do skutecznego funkcjonowania w kontekście różnic kulturowych obejmuje podstawową wiedzę o pochodzeniu etnicznym podopiecznego, świadome zaangażowanie w relację z nim, umiejętność dostosowania się do jego potrzeb i elastyczność w dotarciu do odpowiednich zasobów w jego społeczności. Jedną z głównych przeszkód w budowaniu skutecznej relacji mogą być właśnie bariery międzykulturowe.

\section{Przegląd badań}

Kompetencje kulturowe obejmują zrozumienie i odpowiednie reagowanie na unikalną kombinację zmiennych kulturowych oraz specyficznych wymiarów różnorodności, które profesjonalista i klient (także jego rodzina) wnoszą do interakcji. American Speech-Language-Hearing Association podaje, że kultura i różnorodność kulturowa mogą obejmować czynniki, do których zaliczamy m.in.: wiek, niepełnosprawność,

\footnotetext{
19 J. Ferrell, K.J. Hayward, J. Young, Cultural criminology: An invitation, London 2008, s. 2-3.

20 W. Zalewski, Sprawiedliwość naprawcza - forma demokracji deliberatywnej?, „Białostockie Studia Prawnicze" 2016, z. 21, s. 25-35.

21 National Association of Social Workers, 2015, Standards and Indicators for Cultural Competence in Social Work Practice, https://www.socialworkers.org/LinkClick.aspx?fileticket=PonPTDEBrn4\%3D\&portalid=0 [dostęp: 15.05.2016].
} 
pochodzenie etniczne, tożsamość płciową, pochodzenie narodowe (obejmuje także kulturę, język, dialekt, obywatelstwo i status imigracyjny), rasę, religię, płeć, orientację seksualną. Różnorodność językowa może towarzyszyć różnorodności kulturowej22. Geert Hofstede wskazał wymiary kulturowe, które mają globalne zastosowanie i znajdują odzwierciedlenie we wszystkich aspektach życia. Zaliczył do nich: życie rodzinne, praktyki wychowawcze, sferę edukacji, pracę zarobkową, opiekę zdrowotną. Autor określił również wymiary różnorodności kulturowej, takie jak: indywidualizm i kolektywizm, dystans władzy, męskość i kobiecość, radzenie sobie z problemami, orientacja długo- i krótkoterminowa, zaspokajanie potrzeb i umiar ${ }^{23}$. Wymienione wymiary przejawiają się u poszczególnych osób w różnym natężeniu ze względu na różnice indywidualne, sytuację osobistą, asymilację i akulturację ${ }^{24}$.

Badania Marka Sandersa natomiast pokazują obraz kuratora sądowego, którego kompetencje kulturowe są charakteryzowane poprzez zestawienie specyficznych cech: wykazywanie się szczerością, zaangażowanie w prowadzoną sprawę, znajomość sytuacji kulturowej klienta, prezentowanie postawy pozbawionej osądu, zaradność w rozwiązywaniu problemów ${ }^{25}$. Shulamith L.A. Straussner określa kompetencje etniczno-kulturowe jako zdolność do efektywnego funkcjonowania w kontekście różnic kulturowych. Obejmuje ona podstawową wiedzę na temat pochodzenia etnicznego klienta, zaangażowanie we współpracę z różnorodnymi klientami, umiejętność dostosowania umiejętności zdobytych na szkoleniach do sytuacji klienta oraz umiejętność rozpoznawania i sprawnego wykorzystywania zasobów osobistych klienta ${ }^{26}$. Paul B. Pedersen twierdzi zaś, że profesjonalny doradca (terapeuta, pracownik socjalny, kurator sądowy) powinien zwiększać swoją świadomość kulturową, rozwijać wiedzę na temat różnic i trenować swoje umiejętności. Pedersen postuluje podejmowanie kursów, uczestnictwo w dyskusjach i kontakt z różnorodnymi grupami kulturowymi. Autor pisze, że rozwijanie świadomości jest procesem ciągłym, a rozwijanie umiejętności wielokulturowych jest ostatnim krokiem w procesie osiągania świadomości kulturowej. Pedersen twierdzi, że wykwalifikowany doradca będzie w stanie generować różnorodne rozwiązania w każdej sytuacji i problemie w oparciu o swoją wiedzę i świadomość wielokulturową 27.

Interesujące badania nad empatią kulturową prowadzili Rita Chung i Fred Bernak. Według nich empatia kulturowa to umiejętność wykazania zrozumienia dla światopoglądu klienta i przedstawienia go. Autorzy zaprezentowali sześć kroków tworzenia

22 American Speech-Language-Hearing Association, 2017, Issues in ethics: Cultural and linguistic competence, www.asha.org/Practice/ethics/Cultural-and-Linguistic-Competence/ [dostęp: 18.02.2020].

23 G. Hofstede, Dimensionalizing cultures: The Hofstede model in context " Online Readings in Psychology and Culture" 2011, vol. 2 (1).

24 L. Riquelme, Cultural competence for everyone: A shift in perspectives, „Perspectives on Gerontology” 2013, vol. 18 (2), s. 42-49.

25 M. Sanders, Building bridges instead of walls: Effective cross-cultural counseling, "Corrections Today" 2003, vol. 65 (1), s. 58-59.

26 S.L. Straussner, Ethnic cultures and substance abuse ,",Counselor" 2002, vol. 3 (6), s. 34-37.

27 P.B. Pedersen, Increasing the cultural awareness, knowledge, and skills of culturecentered counselors [w:] Culture and counseling: New Approaches, eds. F.D. Harper \& J. McFadden, s. 31-46, Boston 2003. 
empatii kulturowej. Po pierwsze, doradca musi zrozumieć i zaakceptować kontekst rodziny oraz społeczności klienta ze środowiska odmiennego kulturowo. Po drugie, doradcy powinni próbować adaptować praktyki pomocowe kojarzone z doświadczeniami klienta. Trzeci krok to zdobycie wiedzy na temat historycznego i społeczno-politycznego kontekstu funkcjonowania uczestnika prowadzonych oddziaływań. Po czwarte, istotne jest zdobycie wiedzy na temat funkcjonowania psychospołecznego klientów w nowym dla nich środowisku. Krok piąty obejmuje wrażliwość na problem dyskryminacji, wykorzystywania i rasizmu. A na końcu doradca umożliwia klientowi osiągnięcie stanu poczucia pewności siebie, szczególnie w tych przypadkach, gdzie osoby czują się z różnych powodów zdewaluowane ${ }^{28}$.

Problematyka przygotowania kulturowego kuratorów sądowych wiąże się z kwestią świadomości wielokulturowej oraz sprawiedliwości naprawczej. Mark S. Umbreit i Robert B. Coates podkreślają, że przestępstwo narusza relacje społeczne, a podstawową zasadą sprawiedliwości jest naprawa wyrządzonych szkód i przywrócenie prawidłowych relacji. Ponadto ofiary muszą mieć możliwość włączenia się w proces, a przestępcy powinni mieć możliwość zaakceptowania swoich obowiązków i zobowiązań wobec osoby poszkodowanej oraz społeczności lokalnej. Poważną barierą w tej sytuacji może być kwestia zbyt powierzchownego traktowania przez wymiar sprawiedliwości kwestii odmienności kulturowej sprawcy czy też ofiary. Mark S. Umbreit i R.B. Coates podkreślają, że system wymiaru sprawiedliwości w sprawach karnych musi być bardziej wrażliwy na różne światopoglądy międzykulturowe. Różnice w pochodzeniu kulturowym ofiary, sprawcy, a także członków personelu prowadzącego konferencję naprawczą, mogą prowadzić do nieporozumień. Dlatego M.S. Umbreit i R.B. Coates zalecają zwracanie uwagi na takie elementy, jak bliskość, mowa ciała czy ton mowy. Ponadto wskazują na różnice w poglądach na tematy indywidualne, dotyczące religii czy polityki. Autorzy uważają, że osoby zajmujące się sprawiedliwością naprawczą powinny przestrzegać pewnych wytycznych i promować utrzymywanie stabilnych i dobrych stosunków między różnymi kulturami. Aby taka sytuacja była możliwa, osoby biorące udział w różnych formach sprawiedliwości naprawczej, powinny lepiej poznać siebie poprzez analizę własnej kultury, wyznawanych wartości i posiadanych uprzedzeń, a także prezentowanego stylu komunikacji ${ }^{29}$.

Kwestia dystansu między osobami, podjęta w studiach M.S. Umbreit i R.B. Coates, stała się punktem centralnym w badaniach Deralda Wing Sue i Davida Sue. Autorzy zwrócili uwagę na interesującą kwestię, a mianowicie, że odmienne poczucie bliskości może występować zarówno pomiędzy kulturami, jak i wewnątrz danej kultury. Niektóre sytuacje sprzyjają bliższemu pozycjonowaniu, podczas gdy inne są niewygodne podczas interakcji twarzą w twarz. Autorzy uczulają, że nawet mimikę można interpretować indywidualnie. Na przykład, uśmiech może nie przekazywać tego samego

28 R.C. Chung \& F. Bernak, The relationship of culture and empathy in cross-cultural Counseling, ,Journal of Counseling and Development" 2002, vol. 80, s. 154-159.

29 M.S. Umbreit \& R.B. Coates, Multicultural implications of restorative juvenile justice, „Federal Probation" 1999, vol. 63, s. 44-52. 
znaczenia każdej osobie, podobnie jest z odbiorem kontaktu wzrokowego. W niektórych kulturach uważa się, że utrzymywanie stałego kontaktu wzrokowego jest oznaką braku szacunku, podczas gdy inni uznają to za stosowne ${ }^{30}$.

Znaczącym elementem dla praktyki kuratora sądowego jest również kwestia wartości rodziny, która często jest zróżnicowana kulturowo. Przykładowo - w kulturach latynoskich, azjatyckich i afroamerykańskich wysoko cenione są relacje rodzinne. W kulturach latynoskich - bardzo ważna jest wzajemna troska i ochrona ${ }^{31}$. W kulturach azjatyckich ceni się wzajemne wsparcie, współpracę, dumę i honor. Problemy w kulturach azjatyckich są zazwyczaj rozwiązywane w rodzinie, a wpływy zewnętrzne są przez członków rodziny postrzegane jako niepożądane. W kulturach afroamerykańskich zaś rodzina składa się z dużych gospodarstw domowych, którymi często kieruje starsza kobieta. Powszechny jest tam również system wzajemnej pomocy. W tych przypadkach zaleca się - w kontakcie z uczestnikiem postępowania - wziąć pod uwagę kontekst jego sytuacji rodzinnej i skonsultować się z członkami jego rodziny, przywódcami religijnymi lub innymi przedstawicielami władzy z konkretnych grup kulturowych.

Na problem wielokulturowości w kontekście resocjalizacji zwrócił uwagę również Imogene M. Montgomery. Według autora, potrzeba perspektywy wielokulturowej w systemie resocjalizacji obejmującym nieletnich przestępców powstała w wyniku dostrzeżenia nieproporcjonalnych wskaźników uwięzienia nieletnich w Stanach Zjednoczonych. Pogłębione studia nad tym zjawiskiem udowodniły, że postawy, stereotypy i uprzedzenia kulturowe urzędników wymiaru sprawiedliwości mogą być związane z tym problemem ${ }^{32}$. Podobne wnioski płyną z badań przeprowadzonych przez Petera C. Kratcoskiego i Lucille Dunn Kratcoski. Wynika z nich, że osobiste uprzedzenia i opinie policjantów, miały znaczenie dla sposobu prowadzenia przez nich spraw nieletnich. Sposób rozpatrywania spraw determinowała rasa, płeć i pochodzenie społeczne młodych ludzi, którzy podejrzani byli o wejście w konflikt z prawem ${ }^{33}$. Z tego powodu ważne jest opracowanie mechanizmów, które zapewnią, że osobiste postawy i postrzeganie osób odmiennych kulturowo, nie będą miały negatywnego wpływu na podejmowane decyzje.

Problematykę zderzenia dwóch odmiennych kultur w wyniku relacji profesjonalnej łączącej kuratora zawodowego z podopiecznym, który jest obcokrajowcem, podjął w swoich badaniach Łukasz Wirkus (współautor niniejszego opracowania) ${ }^{34}$. Specyfika tej relacji wynika z konfrontacji różnych kultur, wartości i norm, w tym również prawnych, osadzonych w kontekście obcokrajowców objętych działaniami sądu. Na

30 D.W. Sue \& D. Sue Counseling the culturally different: Theory and practice (3rd ed.), New York 1999.

31 M. Bailey, Georgia Parole Officers Confront Language and Cultural Barriers, 'Corrections Today" 1991, 53(7), s. 118-121.

32 I.M. Montgomery, Multicultural Awareness: Developing Cultural Understanding in the Juvenile Justice System, https://www.ncbi.nlm.nih.gov/books/NBK64481/ [dostęp: 24.04.2020].

33 P.C. Kratcoski, L.D. Kratcoski, Juvenile Delinquency, New York 1990.

34 Projekt Specyfika pracy kuratora sqdowego z cudzoziemcami, objęty finansowaniem Narodowego Centrum Nauki w ramach konkursu Miniatura 2 (grant nr 2018/02/X/HS6/02106). Kierownik projektu: Łukasz Wirkus, Uniwersytet Gdański. 
podstawie jakościowej analizy wywiadów przeprowadzonych z kuratorami sądowymi, Ł. Wirkus wyodrębnił trzy kategorie wymiarów pracy kuratora sądowego z obcokrajowcami - aksjologiczną, prakseologiczną i epistemologiczną. W ramach tych trzech głównych kategorii autor wyodrębnił kilkanaście podkategorii, m.in.: stosunek społeczności lokalnej, współpraca instytucjonalna, metodyka pracy, brak regulacji prawnych, działania intuicyjne, stosowane rozwiązania, sytuacja życiowa, sytuacja edukacyjna, kontekst kulturowy, uprzedzenia, itp. Uzyskane dane pozwalają rekomendować różne rozwiązania w praktyce wykonawczej (struktura dokumentów sądowych, współpraca między służbami w kraju i na terytorium UE, wdrożenie odpowiednich regulacji prawnych, uregulowanie standardów pracy z podopiecznymi cudzoziemcami) oraz praktyce pedagogicznej (rozpoznane bariery komunikacyjne i ich znaczenie dla rzetelności wywiadu, ograniczenia indywidualne w sferze kompetencji kulturowych, przygotowanie zawodowe w ramach aplikacji i proces doskonalenia zawodowego, zaangażowanie w działania inkluzyjne i proces integracji imigrantów).

Poruszany przez nas w niniejszym artykule problem niewystarczającego przygotowania kulturowego kuratorów sądowych stał się bodźcem dla National Center for Juvenile Justice do opracowania modułu szkolenia świadomości kulturowej w ramach Fundamental Skills Training for Juvenile Probation Officers. Moduł szkoleniowy jest przeznaczony do użytku przez trenerów w celu uwrażliwienia kuratorów z krótkim stażem zawodowym na werbalne i niewerbalne różnice komunikacyjne w niektórych kulturach. Moduł szkoleniowy rozpoczyna się od ogólnego wprowadzenia i dyskusji na temat kultury i rasy. Uwzględniono także ćwiczenie polegające na odgrywaniu ról, które podkreśla znaczenie indywidualnego postrzegania kultury oraz tego, jak komunikacja niewerbalna ma kluczowe znaczenie dla zrozumienia konkretnej sytuacji w kontekście różnic kulturowych ${ }^{35}$.

\section{Wnioski}

Kompetencjom kulturowym w polskim wymiarze sprawiedliwości dotychczas poświęcono niewiele uwagi, szczególnie w specyficznym obszarze działalności kurateli sądowej. Myrna Cintron i Won-Jae Lee badali np. oczekiwania pracodawcy w zakresie zatrudniania dwujęzycznych kuratorów. Ankieta przeprowadzona przez kuratorów okręgowych dowiodła, że większość zespołów probacyjnych nie nadążała za trendami krajowymi, a odsetek dwujęzycznych specjalistów jest zbyt niski. Autorzy sugerują, że dwujęzyczni kuratorzy zapewniają poziom usług (interpretacja postanowienia sądu, zrozumienie warunków próby, zasady przestrzegania obowiązków probacyjnych, obowiązkowe i terminowe spotkania z kuratorem), które mogą zwiększyć efektywność pracy kuratorów z osobami odmiennymi kulturowo. Cintron i Lee nie badali bezpośrednio kompetencji wielokulturowych, ale po analizie tendencji demograficznych uznali, że istnieje pilna potrzeba wdrożenia odpowiedniego przygotowania służb

35 I.M. Montgomery, Multicultural Awareness... 
probacyjnych w obszarze kompetencji wielokulturowych ${ }^{36}$. MarshaTarver, Steve Walker i Marvey Wallace zidentyfikowali podstawowe elementy tła kulturowego, chociażby w kontekście usług dla osób doświadczających zjawiska przemocy, co ma przełożenie na działania wymiaru sprawiedliwości w sprawach karnych, tj. instytucji zawieszenia kary i innych środków probacyjnych. Tarver, Walker i Wallace przytaczają znaczenie schematów poznawczych dotyczących poglądów na życie i śmierć, rozwiązywania konfliktów czy funkcjonowania rodziny. Autorzy badań postulują zachowanie prawdziwego szacunku dla kultury drugiejosoby, uznaniegoza ważny sam w sobie irównystatusowizobyczajami dominującej kultury. Kurator powinien być otwarty na różnice i entuzjastycznie do nich nastawiony. Podkreśla się wagę jego wiedzy na temat przestępstwa, procesu sądowego i jego konsekwencji dla probanta ${ }^{37}$. Przykładem dobrych praktyk są działania Służby Więziennej, która podejmuje sporadyczne działania służące zwiększeniu kompetencji międzykulturowych funkcjonariuszy Służby Więziennej w kontekście pracy z obcokrajowcami przebywającymi w izolacji więziennej38. Podobna oferta powinna być standardem w ofercie Krajowej Szkoły Sądownictwa i Prokuratury, a niestety nie jest.

Przegląd badań dotyczących kompetencji kulturowych w pracy kuratorów sądowych, pozwala na stworzenie katalogu rekomendacji obejmujących szereg oczekiwanych rozwiązań w praktyce postępowania wykonawczego:

1) obowiązkowe i wystandaryzowane tłumaczenia dokumentów sądowych np. w języku angielskim, ukraińskim i rosyjskim - mogłyby być one łatwo generowane z systemu informatycznego używanego przez kuratorów sądowych;

2) wdrożenie regulacji prawnych dotyczących zasad współpracy z osobami odmiennymi kulturowo i cudzoziemcami;

3) wdrożenie systemu szkoleń podnoszących kwalifikacje metodyczne (pojęcie różnicy kulturowej, bariery komunikacyjne, ograniczenia indywidualne w sferze kompetencji kulturowych);

4) uwzględnienie zagadnienia kompetencji kulturowych w ramach aplikacji kuratorskiej i procesu doskonalenia zawodowego na kolejnych etapach rozwoju profesjonalnego;

5) zaangażowanie się kuratorów sądowych w działania inkluzyjne na rzecz społeczności odmiennych kulturowo.

Wszystkie one mają na celu przywrócenie podopiecznemu jego człowieczeństwa zarówno w wymiarze indywidualnym, jak i społecznym ${ }^{39}$.

\footnotetext{
36 M. Cintron, W. Lee, Bilingual workforce needs in Texas community supervision and corrections departments: Survey results, „Texas Probation” 2002, VII (1), s. 4-7.

37 M. Tarver, S. Walker i P.H. Wallace, Multicultural Issues in the Criminal Justice System, Boston 2002.

38 https://www.sw.gov.pl/aktualnosc/Warsztaty-zwiekszenia-kompetencji-miedzykulturowychfunkcjonariuszy-Sluzby-Wieziennej-w-kontekscie-pracy-z-obcokrajowcami-przebywajacymi-wizolacji-wieziennej [dostęp: 5.04.2020].

39 A. Babicka-Wirkus, From authoritarianism to emancipation. About the dangerous areas of relationship between the probation officer and the ward „,Polish Journal of Rehabilitation” 2019, vol. 17, s. 103-113.
} 


\section{Literatura}

American Speech-Language-Hearing Association, 2017, Issues in ethics: Cultural and linguistic competence, www.asha.org/Practice/ethics/Cultural-and-Linguistic-Competence/ [dostęp: 18.02.2020].

Babicka-Wirkus A., From authoritarianism to emancipation. About the dangerous areas of relationship between the probation officer and the ward, "Polish Journal of Rehabilitation” 2019, vol. 17.

Bailey M., Georgia Parole Officers Confront Language and Cultural Barriers, "Corrections Today" 1991, nr 53 (7).

Chung R.C., Bernak F., The relationship of culture and empathy in cross-cultural, „Journal of Counseling and Development" 2002, vol. 80.

Cintron M., Lee W., Bilingual workforce needs in Texas community supervision and corrections departments: Survey results, „Texas Probation” 2002, VII (1).

Counseling, „Journal of Counseling and Development" 2002, vol. 80.

Ferrell J., Hayward K.J., Young J., Cultural criminology: An invitation, London 2008.

Hofstede G., Dimensionalizing cultures: The Hofstede model in context, „Online Readings in Psychology and Culture" 2011, vol. 2 (1).

Jedynak T., Stasiak K., Zadania kuratorów sq̨dowych [w:] Zarys metodyki pracy kuratora sądowego, red. K. Stasiak, Warszawa 2018.

Klaus W., Przemoc wobec migrantek przymusowych w Polsce - charakterystyka zjawiska [w:] Bezpieczny dom? Przemoc fizyczna i symboliczna wobec uchodźczyń i uchodźców, red. idem, Warszawa 2014.

Klaus W., Winiarska A., Dyskryminacja i nierówne traktowanie jako zjawisko społeczno-kulturowe, "Studia Biura Analiz Sejmowych" 2011, nr 2.

Kratcoski P.C., Kratcoski L.D., Juvenile Delinquency, New York 1990.

Główny Urząd Statystyczny, Main direction of emigration and immigration in the years 1966-2018 (migration for permanent residence), https://stat.gov.pl/en/topics/population/internationa-migration/main-directions-of-emigration-and-immigration-in-the-years-1966-2018migration-for-permanent-residence,2,2.html [dostęp: 3.04.2020].

Malorny I., Zaniedbanie dziecka w rodzinie migracyjnej - aspekty społeczno-prawne, „Resocjalizacja Polska" 2015, nr 10.

Ministertstwo Sprawiedliwości, Wydział Statystycznej Informacji Zarządczej, Departament Strategii i Funduszy Europejskich Ministerstwa Sprawiedliwości, Dane statystyczne dotyczące liczby prawomocnie skazanych osób dorosłych cudzoziemców według rodzajów przestępstw, płci i wymiaru kary w latach 2016-2018; dane pozyskane na wniosek autorów.

Montgomery I.M., Multicultural awareness: Developing cultural understanding in the juvenile justice system, ,Juvenile Probation Tricks of the Trade" 1992, vol. 1, no. 1, https://www.ncbi.nlm. nih.gov/books/NBK64481/ [dostęp: 24.04.2020].

National Association of Social Workers, Standards and Indicators for Cultural Competence in Social Work Practice, 2015, https://www.socialworkers.org/LinkClick.aspx?fileticket=PonPTDEBrn4\%3D\&portalid=0 [dostęp: 15.05.2016].

Pedersen P.B., Increasing the cultural awareness, knowledge, and skills of culturecentered counselors [w:] Culture and counseling: New Approaches, eds. F.D. Harper, J. McFadden, Boston 2003. 
Riquelme L., Cultural competence for everyone: A shift in perspectives, „Perspectives on Gerontology" 2013, vol. 18 (2).

Rzeplińska I., Buczkowski K., Czarnecka-Dzialuk B., Klaus W., Kossowska A., Wiktorska P., Woźniakowska-Fajst D., Wójcik D., Społeczno-polityczne konteksty współczesnej przestępczości w Polsce, Warszawa 2013.

Rzeplińska I., Włodarczyk-Madejska J., Przestępczość cudzoziemców w Polsce - na podstawie policyjnych statystyk przestępczości [w:] Przestępczość cudzoziemców. Aspekty prawne, kryminologiczne i praktyczne, red. W. Klaus, K. Laskowska, I. Rzeplińska, Warszawa 2017.

Sanders M., Building bridges instead of walls: Effective cross-cultural counseling, "Corrections Today" 2003, vol. 65 (1).

Sobczak K., Więcej cudzoziemców przebywa legalnie w Polsce, https://www.prawo.pl/prawo/ cudzoziemcy-w-polsce-na-poczatku-2020-r-423-tys-osob-przebywalo,497222.html [dostęp: 23.03.2020].

Straussner S.L., Ethnic cultures and substance abuse , "Counselor" 2002, vol. 3 (6).

Sue D.W., Sue D., Counseling the culturally different: Theory and practice, New York 1999.

Tarver M., Walker S., Wallace P.H., Multicultural Issues in the Criminal Justice System, Boston 2002.

Umbreit M.S., Coates R.B., Multicultural implications of restorative juvenile justice, „Federal Probation" 1999, vol. 63.

Urząd do Spraw Cudzoziemców, Zezwolenia na pobyt po I kwartale 2020 r., https://udsc.gov.pl/ zezwolenia-na-pobyt-po-i-kwartale-2020-r/ [dostęp: 15.04.2020].

Wacławiak J., Tendencje zmian w zakresie spraw rejestrowanych w MS-S40. Analiza porównawcza danych z 31.12.2019 do danych z 31.12.2018 roku (na podstawie MS-S40), Warszawa 2020.

Wirkus Ł., Czynności służbowe kuratora rodzinnego z udziałem cudzoziemców - studium przypadku, "Lubelski Rocznik Pedagogiczny" 2019, z. 2.

Wirkus Ł., Specyfika pracy kuratora sq̨dowego z cudzoziemcami, projekt objęty finansowaniem Narodowego Centrum Nauki w ramach konkursu Miniatura 2 (grant nr 2018/02/X/HS6/02106, Uniwersytet Gdański.

Wirkus Ł., The role of the family court in Poland in preventing manifestations of demoralization and juvenile delinquency on the example of preventive and re-socialization activities of probation officers, ,"The Polish Journal of Criminology" 2018, vol. 1.

Zalewski W., Sprawiedliwość naprawcza - forma demokracji deliberatywnej?, „Białostockie Studia Prawnicze" 2016, z. 21.

Zawadka G., Cudzoziemcy popełniaja coraz więcej przestępstw w Polsce , ,Rzeczpospolita" z dnia 22 marca 2018 r., https://www.rp.pl/Przestepczosc/303219904-Cudzoziemcy-popelniaja-corazwiecej-przestepstw-w-Polsce.html [dostęp: 2.04.2020].

\section{Streszczenie}

\section{Anna Babicka-Wirkus, Krzysztof Wirkus}

\section{Nowe wyzwania Kuratorskiej Służby Sądowej. Przygotowanie kulturowe kuratorów sądowych do pracy z obcokrajowcami}

W artykule podejmujemy kwestię współczesnych wyzwań multikulturowych stojących przed kuratorem sądowym. W związku z coraz większym napływem obcokrajowców do Polski 
i zwiększającą się liczbą popełnianych przez nich przestępstw, wymiar sprawiedliwości musi zmierzyć się z coraz większą liczbą spraw, w których sprawca lub poszkodowany czy ofiara są reprezentantami innej kultury. Tego typu sytuacje wymagają posiadania przez reprezentantów wymiaru sprawiedliwości, w tym kuratorów sądowych, odpowiedniego przygotowania kulturowego. Stawiamy tezę, że obecnie poziom tego przygotowania jest niewystarczający. Jest to palący problem, który powinien stać się obiektem pogłębionych studiów i analiz.

\section{Summary}

\section{Anna Babicka-Wirkus, Krzysztof Wirkus}

\section{New challenges of the Curatorial Judicial Service.}

\section{Cultural preparation of probation officers to work with foreigners}

The article is devoted to the issue of contemporary multicultural challenges faced by probation officers. Due to the growing foreigners inflows to Poland and the increasing number of crimes they commit, the judicature must face an increasing number of cases in which the perpetrator or the victim is a representative of another culture. These types of situations require representatives of the judiciary, including probation officers, to have adequate cultural preparation. The authors put forward the thesis that at present the level of this preparation is insufficient. This is a pressing problem that should become the object of in-depth studies and analyzes.

Słowa kluczowe: kurator sądowy, przygotowanie kulturowe, imigranci Keywords: probation officer, cultural preparation, immigrants 